\title{
Transbronchial biopsy from the upper pulmonary lobes is associated with increased risk of pneumothorax - a retrospective study
}

Vladimir Herout', Michaela Heroutova', Zdenek Merta', Ivan Cundrle $\mathrm{Jr}^{2,3}$ and Kristian Brat ${ }^{1 *}$

\begin{abstract}
Background: Pneumothorax (PTX) is one of the most common complications of transbronchial biopsy (TBB). Previous research suggests that upper pulmonary lobe TBB may be associated with increased risk of PTX development. The aim of this study was to compare the risk of PTX after TBB performed from different pulmonary lobes.

Methods: All bronchoscopic records from the period January 1st, 2015 - December 31st, 2017 (from the Department of Respiratory Diseases, University Hospital Brno, Czech Republic) were retrospectively analyzed. Of the 3542 bronchoscopic records, 796 patients underwent TBB and were further analyzed. Basic demographic data, TBB procedure-related factors, smoking history and radiological features were analyzed. Furthermore, in patients who developed PTX, PTX onset, PTX symptoms, distribution of the abnormal radiological findings and duration of hospitalization were also analyzed.

Results: Patients who developed PTX had significantly lower body mass index (BMI) and more than 4 samples taken during procedure (all $p<0.05$ ). TBB performed from the left upper pulmonary lobe was associated with a significant risk of PTX development (OR 2.27; 95\% Cl 1.18-4.35; $p=0.02)$. On the contrary, TBB performed from the right lower lobe was associated with a significant reduction of risk of developing PTX (OR 0.47; 95\% Cl 0.22-0.98; $p=0.04$ ). Logistic regression analysis showed $\mathrm{BMI}(\mathrm{OR} 1.08 ; 95 \% \mathrm{Cl} 1.02-1.16 ; p=0.01)$, left upper lobe as sampling site $(\mathrm{OR} 2.15 ; 95 \% \mathrm{Cl} 1$. $13-4.11 ; p=0.02)$ and more than 4 samples taken (OR $1.91 ; 95 \% \mathrm{Cl} 1.04-3.49 ; p=0.04)$ to be significantly associated with PTX development.

Conclusions: We conclude that TBB from the left upper pulmonary lobe is associated with significantly increased risk of post-procedural PTX. The right lower pulmonary lobe seems to be the safest sampling site to perform TBB. In patients with diffuse-type pulmonary disease, TBB should be performed preferably from the right lower lobe in order to decrease the risk of post-procedural PTX.
\end{abstract}

Keywords: Pneumothorax, Bronchoscopy, Transbronchial biopsy, Upper pulmonary lobe, Pleural pressure

\footnotetext{
* Correspondence: kristian.brat@seznam.cz

${ }^{1}$ Department of Respiratory Diseases, University Hospital Brno and Faculty of

Medicine, Masaryk University, Jihlavska 20, 62500 Brno, Czech Republic

Full list of author information is available at the end of the article
}

(c) The Author(s). 2019 Open Access This article is distributed under the terms of the Creative Commons Attribution 4.0 International License (http://creativecommons.org/licenses/by/4.0/), which permits unrestricted use, distribution, and reproduction in any medium, provided you give appropriate credit to the original author(s) and the source, provide a link to the Creative Commons license, and indicate if changes were made. The Creative Commons Public Domain Dedication waiver (http://creativecommons.org/publicdomain/zero/1.0/) applies to the data made available in this article, unless otherwise stated. 


\section{Background}

Transbronchial lung biopsy (TBB) is a procedure performed during flexible bronchoscopy with the use of biopsy forceps. Usually, the purpose is to obtain samples of peripheral lung tissue in order to diagnose interstitial lung disease or to specify the character of a peripheral lung lesion. The first experience with TBB using flexible bronchoscopy was published by Levin et al. in 1974 [1].

The most common complications of TBB are pneumothorax (PTX) and bleeding. An overall complication rate was reported to be around 6\% [2]. The incidence of PTX after TBB was reported to be $1-6 \%$ [3]. The main risk factors include emphysema, COPD and positive pressure ventilation $[4,5]$. In a study by Huang et al., TBB performed from the upper pulmonary lobes tended to be a potential risk factor for PTX development when compared to other locations [4]. However, in this study, the group of patients with PTX was too small to gain statistical significance $[4,5]$.

An outpatient bronchoscopy procedure is usually performed in a supine position. However, if no complications occur within $2 \mathrm{~h}$ from the procedure, the patient is allowed to leave the health-care facility (in an upright position). In a healthy human in an upright position, the pleural pressure is most negative in the apical parts and least negative in the basal parts of the pleural space [6]. A second point is that the alveoli in the upper parts of the lung are larger than those in the lower parts. This is the consequence of the apico-basal pressure gradient in the pleural cavity resulting in a higher surface tension of the apical lung tissue [7]. It is also a possible reason for the subpleural blebs formation in the apex of the lungs [6]. The existence of the apico-basal gradient in pleural pressure may favour the development post-procedural PTX after TBB from the upper pulmonary lobes [6]. We hypothesized that the incidence of PTX will be higher in patients after TBB performed from the upper than from lower pulmonary lobes. Accordingly, the aim of this study was to evaluate the incidence of PTX in TBB performed from diffent lung lobes.

\section{Methods}

\section{Background}

Department of Respiratory Diseases, University Hospital Brno, Czech Republic, is a university-type facility concentrating the most difficult respiratory cases (i.e. patients with lung cancer, interstitial lung disease, cystic fibrosis etc.) from an area populated by ca 1.5 million inhabitants. Annually, cca. 1100-1300 bronchoscopic procedures are performed in the institution. Of these, cca. 250-300 patients annually undergo TBB. The most frequent indication for TBB include suspicion of lung cancer, differential diagnosis of interstitial lung disease and infiltrates of unknown significance present on chest radiograph or lung CT scan.
Flexible fiberoptic bronchoscopies were performed in light sedation (using $0.25 \mathrm{mg}$ of alprazolam or $3.75 \mathrm{mg}$ of midazolam) and using topical anesthetics (lidocaine and trimecaine or bupicavaine) in accordance with the 2013 British Thoracic Society (BTS) guidelines [3]. Flexible fiberoptic bronchoscopes type BF-1 T180 (Olympus, Japan) and EB-1975 K (Pentax Medical, Japan) were used. Fluoroscopically unguided TBB were performed in accordance with the BTS guidelines [3] using the 1.8 mm-diameter Single Use-Biopsy Forceps - type NBF1211018120 (Micro-Tech, China).

\section{Study population}

All bronchoscopic records from the period between January 1st, 2015 and December 31st, 2017 were retrospectivelly analyzed. Patients with TBB were included in the study. From the patient's records, demographic data (age, weight, height, BMI, gender), PTX incidence, indication for TBB, number of samples taken during TBB, area of TBB sampling (pulmonary lobe), smoking history and CT or chest X-ray (CXR) signs of emphysema were analyzed. Furthermore, in patients who developed PTX, onset of PTX $(<24 \mathrm{~h},>24 \mathrm{~h})$, PTX symptoms (cough, chest pain, desaturation $>5 \%$, dyspnoea or none), PTX treatment (conservative treatment, desuflation, chest tube insertion), hospital length of stay (LOS) and mortality were analyzed.

\section{Statistical methods}

The Shapiro-Wilk test was used to evaluate normality. Comparisons between patients with and without PTX were made by the Student t-test and Mann-Whitney U test. Differences in proportions were tested by the $2 \times 2$ table and two-tailed Fisher exact test. Multivariate stepwise logistic regression was used to analyze which of the parameters was independently associated with the development of PTX. Parameters that were significantly different between both groups (with PTX vs. without PTX) and had OR $>1.00$ were included in the logistic regression model (BMI, number of samples taken, sampling site). Data are summarized as mean \pm standard deviation (SD); $p$ values $<0.05$ were considered statistically significant. Statistica software 12.0 (StatSoft Inc., Prague, Czech Republic) was used for statistical analysis.

\section{Results}

A total of 3542 bronchoscopic records were analyzed. Seven hundred and ninety-six patients underwent the TBB procedure. Out of the analyzed 796 patients, 49 patients (6.16\%) developed PTX. Basic demographic data and procedure-related characteristics are presented in Table 1 . Of the 796 patients, 58\% were men, 55\% were current or past smokers, mean age was 63 years. The most frequent indication for TBB was a nodular lesion 
Table 1 Basic characteristics of the study cohort $(n=796)$

\begin{tabular}{|c|c|}
\hline Age (years) & $63 \pm 13$ \\
\hline Male No. (\%) & $461(58)$ \\
\hline BMI $\left(\mathrm{kg} / \mathrm{m}^{2}\right)$ & $28 \pm 14$ \\
\hline No of samples $\geq 4$ No. (\%) & $199(25)$ \\
\hline PTX No. (\%) & $49(6)$ \\
\hline \multicolumn{2}{|l|}{ Indication to TBB } \\
\hline Nodular lesion (suspicion of tumour) No. (\%) & $385(48)$ \\
\hline Diffuse lung disease (suspicion of pulmonary fibrosis) No. (\%) & $187(24)$ \\
\hline Infiltrates of unknown etiology No. (\%) & $165(21)$ \\
\hline Other No. (\%) & $59(7)$ \\
\hline \multicolumn{2}{|l|}{ Sampling location (pulmonary lobe) } \\
\hline Sample from RUL No. (\%) & $136(17)$ \\
\hline Sample from RML No. (\%) & $122(15)$ \\
\hline Sample from RLL No. (\%) & $252(32)$ \\
\hline Sample from LUL No. (\%) & $126(16)$ \\
\hline Sample from LLL No. (\%) & $114(14)$ \\
\hline Sample from > 2 lobes No. (\%) & $46(6)$ \\
\hline Emphysema on lung CT or CXR No. (\%) & $218(27)$ \\
\hline Smoking No. (\%) & $443(55)$ \\
\hline
\end{tabular}

(48\%) followed by diffuse lung disease (24\%); an upper lobe was used as sampling site in $33 \%$, middle lobe in $15 \%$ and a lower lobe in $46 \%$ of the cohort. Six percent of patients underwent TBB from more than one lobe. A comparison between patient groups with and without PTX is shown in Table 2. Patients who developed PTX had significantly lower BMI, more than 4 samples taken during procedure. Furthermore, TBB was more frequently performed from the left upper lobe in subjects with PTX. On the contrary, the right lower lobe was more frequently used as a site for TBB in subjects without PTX. In patients with diffuse-type lung pathology $(n=187)$, the diagnostic yield of TBB was $52.9 \%$ in our cohort. In patients with nodular lesions, the diagnostic yield of the TBB procedure was $40.5 \%$ in our cohort.

A stepwise logistic regression (BMI, number of samples taken and sampling site were used in the model) is shown in Table 3. All 3 included variables were significantly associated with PTX development; LUL sampling site had the highest OR (OR 2.15; 95\% CI $1.13-4.11 ; p=0.02)$.

Of the 49 PTX cases, 31 patients (63\%) had early onset of PTX while 18 cases $(37 \%)$ were diagnosed $>24$ h after the procedure. In twenty-seven of the 49 PTX patients (55\%), PTX was clinically significant and warranted chest tube insertion. Hospital LOS was significantly longer in patients with thoracic drainage when compared to patients treated conservatively ( $7 \pm 4$ vs. $2 \pm 1$ vs. days; $p<0.01)$. Of the 27 cases of PTX treated by thoracic drainage, 11 patients (41\%) had undergone left upper lobe biopsy and 4 of these 11 patients (36\%) had pathological lesions present also in other pulmonary lobes. Choosing a different sampling site for TBB in these 4 patients might have decreased the number of clinically significant PTX (i.e. requiring chest tube insertion) by about $15 \%$ in our cohort.

\section{Discussion}

The major finding of this study was that the left upper pulmonary lobe TBB, BMI and more than 4 samples taken were significantly associated with increased odds of post-procedural PTX. In contrast, the odds of postprocedural PTX were the lowest with TBB done from the right lower lobe.

In our study, the incidence of PTX was $6.16 \%$ which is comparable to the data from the BTS guideline (PTX incidence reported to be 1-6\%) [3], the Sindhwani et al. study (10.2\%) [8], from the COMET Trial (7.2\%) [9] and from the Ibrahim et al. study (9.8\%) [10]. Our cohort included $48 \%$ of patients with nodular lesions and there was an insignificant trend towards more nodular lesions TBB in the PTX group. Nodular lesions are strongly associated with the presence of pulmonary emphysema and vice versa [11], which may increase the risk of postprocedural PTX development [9, 12]. Indeed, compared to patients without PTX, in patients with PTX there was also an insignificant trend towards more pulmonary emphysema in our cohort. The ideal number of TBB samples that should be taken at each procedure remains controversial, some authors concluded that it has no relevance to risk of post-procedural PTX [9]. In our analysis, the number of samples taken during TBB was significantly associated with PTX development and remained a significant factor of PTX development also in the logistic regression analysis.

In our study, the odds of PTX development were the highest in patients with TBB performed from the left upper lobe. In contrast, the odds were the lowest in patients with TBB performed from the right lower lobe. The observed apico-basal difference may be explained by the vertical pleural pressure gradient. In a healthy human in an upright position, the pleural pressure is the lowest (i.e. most negative) in the apical parts and the highest (i.e. least negative) in the basal parts. The pressure difference between the pulmonary apex (about -12 $\mathrm{cm} \mathrm{H}_{2} \mathrm{O}$ ) and the base (about $-2 \mathrm{~cm} \mathrm{H}_{2} \mathrm{O}$ ) may be up to 8-10 $\mathrm{cmH}_{2} \mathrm{O}$ [6]. Therefore, a more negative pressure in the apical parts may predispose to the easier PTX development in patients undergoing TBB from the upper pulmonary lobes. Interestingly, there also appears to be a 
Table 2 Comparison of patients with and without PTX

\begin{tabular}{|c|c|c|c|c|c|}
\hline Parameter & without PTX $(n=747)$ & with PTX $(n=49)$ & OR & $95 \% \mathrm{Cl}$ & $p$ \\
\hline Age (years) & $63 \pm 13$ & $66 \pm 11$ & 0.98 & $0.95-1.00$ & 0.06 \\
\hline Male No. (\%) & $430(58)$ & $31(63)$ & 1.27 & $0.70-2.31$ & 0.46 \\
\hline BMI $\left(\mathrm{kg} / \mathrm{m}^{2}\right)$ & $28 \pm 15$ & $25 \pm 5$ & 1.09 & $1.02-1.16$ & 0.01 \\
\hline No. of samples $\geq 4$ No. (\%) & $180(24)$ & $19(39)$ & 2.00 & $1.10-3.63$ & 0.03 \\
\hline \multicolumn{6}{|l|}{ Indication to TBB } \\
\hline Nodular lesion (suspicion of tumour) No. (\%) & $355(47)$ & $30(61)$ & 1.74 & $0.96-3.15$ & 0.08 \\
\hline Diffuse lung disease (suspicion of pulmonary fibrosis) No. (\%) & $173(23)$ & $14(29)$ & 1.33 & $0.70-2.52$ & 0.49 \\
\hline Infiltrates of unknown etiology No. (\%) & $162(22)$ & $3(6)$ & 0.24 & $0.07-0.77$ & $<0.01$ \\
\hline Other No. (\%) & $57(8)$ & $2(4)$ & 0.52 & $0.12-2.18$ & 0.42 \\
\hline \multicolumn{6}{|l|}{ Sampling location (pulmonary lobe) } \\
\hline Sample from RUL No. (\%) & $124(17)$ & $12(25)$ & 1.63 & $0.83-3.21$ & 0.17 \\
\hline Sample from RML No. (\%) & $116(15)$ & $6(12)$ & 0.76 & $0.32-1.82$ & 0.56 \\
\hline Sample from RLL No. (\%) & $243(33)$ & $9(18)$ & 0.47 & $0.22-0.98$ & 0.04 \\
\hline Sample from LUL No. (\%) & $112(15)$ & $14(29)$ & 2.27 & $1.18-4.35$ & 0.02 \\
\hline Sample from LLL No. (\%) & $109(14)$ & $5(10)$ & 0.67 & $0.26-1.71$ & 0.42 \\
\hline Sample from > 2 lobes No. (\%) & $43(6)$ & $3(6)$ & 1.07 & $0.32-3.57$ & 1.00 \\
\hline Emphysema No. (\%) & $199(27)$ & $19(39)$ & 1.74 & $0.96-3.17$ & 0.07 \\
\hline Smoking No. (\%) & $412(55)$ & $31(63)$ & 1.40 & $0.77-2.55$ & 0.30 \\
\hline
\end{tabular}

$B M I$ body mass index, $\mathrm{kg}$ kilogram, LLL left lower lobe, LUL left upper lobe, $m$ meter, No. number, OR Odds Ratio, RLL right lower lobe, RML right middle lobe, $R U L$ right upper lobe; $95 \%$ Cl 95\% Confidence Interval

difference in pleural pressure between the right and the left lung. The right lung is heavier and the pleural pressure seems to be higher in the basal part of the right lung when compared to the basal parts of the left lung [13]. This side-difference may explain the right lower lobe TBB association with the lowest odds of PTX development.

The higher incidence of PTX in subjects with TBB from the upper lobe is in concensus with the study of Huang et al. and Fernandez-Bussy et al. [12, 14]. In a study by Huang et al., 13 cases of post-procedural PTX out of 399 procedures were reported after endobronchial ultrasound-guided TBB [12]. In this study, univariate analysis revealed that pulmonary emphysema was associated with increased risk of PTX. Importantly, of the 13 PTX cases, 10 events occured after TBB from the upper lobes and only 3 from the middle and lower lobes. However, this clear trend was statistically insignificant $(p=0.084)$, probably due to the low number of PTX cases in the cohort. In the same study, the multivariate

Table 3 Logistic regression

\begin{tabular}{llll}
\hline parameter & OR & $95 \% \mathrm{Cl}$ & $\mathrm{p}$ \\
\hline BMI $(\mathrm{kg} / \mathrm{m} 2)$ & 1.08 & $1.02-1.16$ & 0.01 \\
No. of samples $\geq 4$ & 1.91 & $1.04-3.49$ & 0.04 \\
Sample from LUL & 2.15 & $1.13-4.11$ & 0.02 \\
\hline
\end{tabular}

$B M I$ body mass index, $k g$ kilogram, LUL left upper lobe, $m$ meter, No. number analysis showed that pulmonary emphysema was the strongest independent risk factor of post-TBB PTX with OR $55.09(p<0.001)$ while a location of the lesion in the upper lobes had an OR 3.34 albeit insignificant $(p=0.149)$ due to small number of PTX cases [12].

In the study by Fernandez-Bussy et al., upper or middle lobe procedure was found to be an independent risk factor of post-procedural complications (OR 1.69) [14]. This did not reach statistical significance as the study was severely underpowered; only 3 cases of PTX were reported [14].

In contrast to our study, Izbicki et al. reported 8 cases of post-procedural PTX, of which none resulted from an upper pulmonary lobe TBB [15]. However, in most of the studies, the location of TBB sampling was not evaluated in relation to PTX development $[2,9,12,16]$.

The diagnostic yield of TBB (with no fluoroscopy guidance) in our study cohort was $52.9 \%$ for diffuse parenchymal lung diseases and $40.5 \%$ for nodular lesions, respectively. This is comparable to previous reports where: Hernandez Borge et al. reported an overall diagnostic yield of $42 \%$ [17], in a Swiss study (Descombes et al.), the diagnostic yield for diffuse-type lung pathologies was $50 \%$ [18]. In contrast, the BTS guideline cited 2 studies where the sensitivity was up to $67-74 \%$ [3]. For peripheral lung lesions, a very wide variation rate accross different studies (16-80\%) has been reported [19]. In the BTS guideline, diagnostic accuracy of TBB for malignant 
lesions was around 45\%, while in the Swiss study (Descombes et al.) only around 29\% [18].

Our study had several limitations. First, it was a retrospective study. Therefore, commenting on causality between the site of TBB and PTX development is difficult. Second, in our cohort, there was an insignificant trend towards more nodular lesion TBBs in the PTX group. Therefore, several TBBs in our cohort could not have been performed from lower lobes in order to prevent PTX development. We suggest that in case the TBB could not be performed from the lower lobes it should at least increase the awareness of PTX development.

Third, all procedures included in the current study performed transbronchial biopsy without fluoroscopy. It is unknown if these results apply to centers that use fluoroscopy as part of their standard practice, however, there is no evidence that fluoroscopy changes the incidence or location of pneumothorax during TBB [3, 15, 20-22].

Last, this was a retrospective study and we were not able to measure the distance of nodules from visceral pleura in all patients with nodular lesions, as some CT scans were no longer available for review. In patients with peripheral lesions, the risk of PTX development may be higher than in patients with more centrally situated lesions. However, we believe the majority of patients with peripheral lesions underwent a CT-guided transthoracic needle biopsy as recomended [23] leaving mostly those patients with more centrally situated lesions in our study cohort. Indeed, in patients with a nodular lesion and with PTX (all the 30 patients had CT scans still available for review), the mean lesion distance from the visceral pleura was $31 \mathrm{~mm}$ vs 29 mm for non-PTX patients $(p=0.08)$.

\section{Conclusions}

We conclude that TBB from the left upper pulmonary lobe is associated with significantly increased risk of post-procedural PTX development. In contrast, right lower pulmonary lobe appears to be the safest sampling site to perform TBB.

In patients with a solitary nodular lesion, TBB should be performed under fluoroscopy guidance (if available). The use of fluoroscopy increases the diagnostic yield and may decrease the risk of procedure-related PTX [3].

In patients with a diffuse-type (parenchymal) lung disease, the use of fluoroscopy does not improve the diagnostic yield of TBB and is not routinely recommended. Our data show that the risk of post-TBB PTX may be decreased by choosing the lower lobes (preferably RLL) as sampling site instead of an upper-lobe procedure.

In patients with nodular lesions in multiple locations (e.g. multiple metastases) and where fluoroscopy is not available, the lower lobes should be chosen preferably as a sampling site.
A prospective study addressing the impact of TBB sampling site on risk of postprocedural PTX in a more strictly defined study population (e.g. solely diffuse lung disease patients or solely patients with nodular lesions) with and without fluoroscopy guidance would be beneficial.

\begin{abstract}
Abbreviations
BMI: Body Mass Index; CT: Computed Tomography; LOS: Length of stay; PTX: Pneumothorax; TBB: Transbronchial biopsy

\section{Acknowledgements}

The authors would like to thank the staff of the Endoscopy Center, University Hospital Brno, for cooperation during data search, namely to Lenka Vitesnikova, Renata Vrankova and Anna Martincova.

\section{Funding}

Supported by Ministry of Health, Czech Republic - conceptual development of research organization (FNBr, 65269705) and by the project no. LQ1605 from the National Program of Sustainability II (MEYS CR) and by the project FNUSA-International Clinical Research Center no. CZ.1.05/1.1.00/02.0123 (OP VaVpl). Supported by the Czech Pneumological and Phthisiological Society (publication fee grant).
\end{abstract}

\section{Availability of data and materials}

All baseline data sheets are available from the corresponding author on reasonable request.

\section{Authors' contributions}

KB designed the study, contributed to the data collection, analysis and interpretation and writing of the manuscript. $\mathrm{VH}$ contributed to the data collection and writing of the manuscript. IC contributed to the data analysis and interpretation and writing of the manuscript. $\mathrm{MH}$ contributed to the data collection and writing of the manuscript. ZM contributed to the data interpretation and writing of the manuscript. All authors approved the final version of the manuscript.

\section{Ethics approval and consent to participate}

Written informed consent was part of each bronchoscopic procedure and was signed by every patient. The study has been approved by the institutional Ethics Committee of the University Hospital Brno. Date of approval: March 7th, 2018; project registration number (University Hospital Brno): 02-070318.

Consent for publication

Not applicable.

Competing interests

The authors declare no conflicts of interest in relation to the presented study.

\section{Publisher's Note}

Springer Nature remains neutral with regard to jurisdictional claims in published maps and institutional affiliations.

\section{Author details}

${ }^{1}$ Department of Respiratory Diseases, University Hospital Brno and Faculty of Medicine, Masaryk University, Jihlavska 20, 62500 Brno, Czech Republic. ${ }^{2}$ Department of Anesthesiology and Intensive Care, St. Anne's University Hospital and Faculty of Medicine, Masaryk University, Brno, Czech Republic. ${ }^{3}$ International Clinical Research Center, St. Anne's University Hospital, Brno, Czech Republic.

Received: 19 December 2018 Accepted: 21 February 2019

Published online: 01 March 2019

\section{References}

1. Levin DC, Wicks AB, Ellis JH. Transbronchial lung biopsy via the fibreoptic bronchoscope. Am Rev Respir Dis. 1974;110:4-12. 
2. Milman N, Faurschou P, Munch EP, Grode G. Transbronchial lung biopsy through the fibre optic bronchoscope. Results and complications in 452 examinations. Respir Med. 1994;88:749-53.

3. Du Rand IA, Blaikley J, Booton R, Chaudhuri N, Gupta V, Khalid S, et al. British Thoracic Society bronchoscopy guideline group. British Thoracic Society guideline for diagnostic flexible bronchoscopy in adults: accredited by NICE. Thorax. 2013;68(Suppl 1):i1-i44.

4. Huang CT, Ruan SY, Liao WY, Kuo YW, Lin CY, Tsai YJ, et al. Risk factors of pneumothorax after endobronchial ultrasound-guided transbronchial biopsy for peripheral lung lesions. PLoS One. 2012;7:e49125.

5. Jain P, Hadique S, Mehta AC. Transbronchial lung biopsy. In: Mehta A, Jain P, editors. Interventional bronchoscopy. Totowa, NJ: Humana Press; 2013. p. 15-44.

6. Zielinska-Krawczyk M, Krenke R, Grabczak EM, Light RW. Pleural manometryhistorical background, rationale for use and methods of measurement. Respir Med. 2018:136:21-8.

7. Lai-Fook SJ. Pleural mechanics and fluid exchange. Physiol Rev. 2004;84(2): 385-410.

8. Sindhwani G, Shirazi N, Sodhi R, Raghuvanshi S, Rawat J. Transbronchial lung biopsy in patients with diffuse parenchymal lung disease without 'idiopathic pulmonary fibrosis pattern' on HRCT scan - experience from a tertiary care center of North India. Lung India. 2015;32:453-6.

9. Galli JA, Panetta NL, Gaeckle N, Martinez FJ, Moore B, Moore T, et al. COMET investigators. Pneumothorax after Transbronchial biopsy in pulmonary fibrosis: lessons from the multicenter COMET trial. Lung. 2017;195:537-43.

10. Ibrahim AS, Allangawi MH, Sattar HA, Mobyed HS, Almohammed AA. Indications, diagnostic yields and complications of transbronchial biopsy over 5 years in the State of Qatar. Saudi Med J. 2005;26:641-5.

11. Bae K, Jeon KN, Lee SJ, Kim HC, Ha JY, Park SE, et al. Severity of pulmonary emphysema and lung cancer: analysis using quantitative lobar emphysema scoring. Medicine (Baltimore). 2016;95:e5494.

12. Huang $Y$, Huang $H, L i Q$, Browning RF, Parrish S, Turner JF Jr, et al. Transbronchial lung biopsy and pneumothorax. J Thorac Dis. 2014; 6(Suppl 4):S443-7.

13. Rabinowitz JG, Kongtawng T. Loculated interlobar air-fluid collection in congestive heart failure. Chest. 1978;74:681-3.

14. Fernández-Bussy S, Labarca G, Zagolin M, Oyonarte M, Isamit D, Jalilie A, et al. Immediate complications following flexible bronchoscopy: retrospective analysis of 1079 procedures. Rev Med Chil. 2014;142:299-304.

15. Izbicki G, Romem A, Arish N, Cahan C, Azulai H, Chen-Shuali C, et al. Avoiding routine chest radiography after Transbronchial biopsy is safe. Respiration. 2016;92:176-81.

16. Tukey MH, Wiener RS. Population-based estimates of transbronchial lung biopsy utilization and complications. Respir Med. 2012;106:1559-65.

17. Hernández Borge J, Alfageme Michavila I, Muñoz Méndez J, Villagómez Cerrato R, Campos Rodríguez F, Peña Griñán N. Factors related to diagnostic yield and complications of transbronchial biopsy. Arch Bronconeumol. 1998; 34:133-41.

18. Descombes E, Gardiol D, Leuenberger P. Transbronchial lung biopsy: an analysis of 530 cases with reference to the number of samples. Monaldi Arch Chest Dis. 1997:52:324-9.

19. Rittirak W, Sompradeekul S. Diagnostic yield of fluoroscopy-guided transbronchial lung biopsy in non-endobronchial lung lesion. J Med Assoc Thail. 2007;90(Suppl 2):68-73.

20. Anders GT, Johnson JE, Bush BA, Matthews JI. Transbronchial biopsy without fluoroscopy. A seven-year perspective. Chest. 1988;94:557-60.

21. Izbicki G, Shitrit D, Yarmolovsky A, Bendayan D, Miller G, Fink G, et al. Is routine chest radiography after transbronchial biopsy necessary?: a prospective study of 350 cases. Chest. 2006;129:1561-4.

22. de Fenoyl O, Capron F, Lebeau B, Rochemaure J. Transbronchial biopsy without fluoroscopy: a five year experience in outpatients. Thorax. 1989;44: 956-9.

23. Gasparini S, Bonifazi M, Wang K-P. Transbronchial needle aspirations vs. percutaneous needle aspirations. J Thorac Dis. 2015;7:S300-3.

\section{Ready to submit your research? Choose BMC and benefit from:}

- fast, convenient online submission

- thorough peer review by experienced researchers in your field

- rapid publication on acceptance

- support for research data, including large and complex data types

- gold Open Access which fosters wider collaboration and increased citations

- maximum visibility for your research: over $100 \mathrm{M}$ website views per year

At BMC, research is always in progress.

Learn more biomedcentral.com/submissions 